\title{
Characterization of potentially probiotic lactic acid bacteria and bifidobacteria isolated from human colostrum
}

\author{
Wenjun Liu, ${ }^{1,2,3 *}$ Meixuan Chen, ${ }^{1,2,3 *}$ Lana Duo, ${ }^{1,2,3}$ Jicheng Wang, ${ }^{1,2,3}$ Shuai Guo, ${ }^{1,2,3}$ Haotian Sun, ${ }^{1,2,3}$ \\ Bilige Menghe, ${ }^{1,2,3}+$ and Heping Zhang ${ }^{1,2,3} \dagger$ \\ ${ }^{1}$ Key Laboratory of Dairy Biotechnology and Engineering, Ministry of Education of China, Inner Mongolia Agricultural University, Hohhot, 010018 , \\ China \\ ${ }^{2}$ Key Laboratory of Dairy Products Processing, Ministry of Agriculture and Rural Affairs of China, Inner Mongolia Agricultural University, Hohhot, \\ 010018, China \\ ${ }^{3}$ Inner Mongolia Key Laboratory of Dairy Biotechnology and Engineering, Inner Mongolia Agricultural University, Hohhot, 010018, China
}

\begin{abstract}
Breast milk is the main source of nutrition for infants; it contains considerable microflora that can be transmitted to the infant endogenously or by breastfeeding, and it plays an important role in the maturation and development of the immune system. In this study, we isolated and identified lactic acid bacteria (LAB) from human colostrum, and screened 2 strains with probiotic potential. The LAB isolated from 40 human colostrum samples belonged to 5 genera: Lactobacillus, Bifidobacterium, Streptococcus, Enterococcus, and Staphylococcus. We also isolated Propionibacterium and Actinomyces. We identified a total of 197 strains of LAB derived from human colostrum based on their morphology and 16S rRNA sequence, among them 8 strains of Bifidobacterium and 10 strains of Lactobacillus, including 3 Bifidobacterium species and 4 Lactobacillus species. The physiological and biochemical characteristics of strains with good probiotic characteristics were evaluated. The tolerances of some of the Bifidobacterium and Lactobacillus strains to gastrointestinal fluid and bile salts were evaluated in vitro, using the probiotic strains Bifidobacterium lactis BB12 and Lactobacillus rhamnosus GG as controls. Among them, B. lactis Probio-M8 and L. rhamnosus Probio-M9 showed survival rates of 97.25 and $78.33 \%$ after digestion for $11 \mathrm{~h}$ in artificial gastrointestinal juice, and they exhibited growth delays of 0.95 and $1.87 \mathrm{~h}$, respectively, in $0.3 \%$ bile salts. These two strains have the potential for application as probiotics and will facilitate functional studies of probiotics in breast milk and the development of human milk-derived probiotics.
\end{abstract}

Received September 17, 2019.

Accepted December 26, 2019.

*These authors contributed equally to this work.

†Corresponding authors: mhblg@163.com and hepingdd@vip.sina .com
Key words: human colostrum, lactic acid bacteria, isolation/identification, artificial gastric juice, bile salt

\section{INTRODUCTION}

Human breast milk contains many essential nutrients, including immune factors, lipids, oligosaccharides, microRNAs, hormones, and many other biologically active components (Hennet and Borsig, 2016); it is considered the best source of nutrition for infants (Verhasselt, 2010). Human breast milk was long thought to be aseptic, and the presence of bacteria was presumed to be a result of contamination (Murphy et al., 2017). The microorganisms were thought to originate from pregnant women with mastitis or from the skin, vagina, intestine, or oral cavity (Kvist, 2010). However, at least some of the bacteria present in the maternal gut could reach the mammary gland via an endogenous route (Rescigno et al., 2001; Martín et al., 2004; Fernández et al., 2013). The first descriptions of the bacterial diversity of human milk from healthy women in 2003 were based on in vitro culturing methods (Heikkilä and Saris, 2003; Martín et al., 2003). Since then, other studies of bacterial communities of human milk using culturedependent and culture-independent methods have been published (Kozak et al., 2015; Ruiz et al., 2019).

Human milk from healthy women contains bacterial flora of approximately $10^{3}$ to $10^{4} \mathrm{cfu} / \mathrm{mL}$ and is a persistent source of commensal bacteria for infants (Arici et al., 2004). More than 200 bacterial taxa have been isolated from breast milk, principally facultative anaerobes such as Staphylococcus, Streptococcus, Enterococcus, Lactobacillus, and Bifidobacterium (Heikkilä and Saris, 2003; Sakwinska et al., 2016). Viable commensally mutualistic or potentially probiotic bacteria are present in healthy human milk (Fernández et al., 2013). They contribute to the maturation of the digestive and immune systems in the developing infant and play an irreplaceable role in promoting growth and 
development. Bifidobacteria in particular participate in defense against pathogens by preventing adhesion to the gut epithelium during a vulnerable period in life, when the infant's own defenses are immature (Bode, 2012; Chiu et al., 2014). In addition, breast milk bacteria can maintain a healthy gut microbiota and have the potential to promote maternal and infant health, including the prevention or treatment of mastitis (Arroyo et al., 2010; Fernández et al., 2016), the promotion of normal gut bacterial colonization in preterm neonates (Escribano et al., 2014), and the prevention of diarrhea (Shin et al., 2018).

Several species of Bifidobacterium (e.g., Bifidobacterium breve and Bifidobacterium longum) and Lactobacillus (e.g., Lactobacillus gasseri, Lactobacillus salivarius, Lactobacillus rhamnosus, Lactobacillus plantarum, and Lactobacillus fermentum) have been isolated and identified (Amezcua López et al., 2019; Ruiz et al., 2019). The European Food Safety Authority granted them Qualified Presumption of Safety status, and the United States Food and Drug Administration granted them Generally Recognized as Safe status.

Thus far, numerous probiotics have been isolated from the human gastrointestinal tract and from dairy products. However, lactic acid bacteria (LAB) with excellent probiotic properties from human milk have rarely been identified. If bacteria with the ability to confer health benefits were isolated from breast milk, they would be attractive probiotic organisms. These bacteria would fulfill some of the main criteria generally recommended for human probiotics, including human origin, a history of safe, prolonged intake by infants, and adaptation to dairy substrates (Martín et al., 2003). Such strains could be used in the development of probiotic products and health food. Therefore, we isolated and identified LAB in human milk and screened them for potential probiotic strains.

In the present study, we isolated LAB and bifidobacteria from human colostrum using a traditional pure culture method, and we conducted gastric acid and bile salts tolerance tests in a simulated gastrointestinal environment in vitro. We evaluated the physiological and biochemical characteristics of 2 potential probiotics, such as carbohydrate utilization and growth curve. The findings point to microbial species or strains that may be suitable for development as probiotics for infants who cannot breastfeed.

\section{MATERIALS AND METHODS}

\section{Sample Collection}

Samples of human colostrum were collected from 40 healthy lactating volunteers of Han and Mongolian eth- nicity in Inner Mongolia. Samples were collected using $50 \mathrm{~mL}$ sterile sampling tubes or storage bags, stored at $4^{\circ} \mathrm{C}$ using an ice box, and transported to the laboratory within $2 \mathrm{~h}$ for bacterial isolation.

\section{Isolation and Purification of LAB}

Breast milk samples of $0.5 \mathrm{~mL}$ were diluted to $10^{-3}$ and $10^{-4}$ in 10 -fold steps in $4.5 \mathrm{~mL}$ of PBS $(8.0 \mathrm{~g}$ of NaCl$/ \mathrm{L}$, $0.2 \mathrm{~g}$ of $\mathrm{KH}_{2} \mathrm{PO}_{4} / \mathrm{L}$, and $1.15 \mathrm{~g}$ of $\mathrm{Na}_{2} \mathrm{HPO}_{4} / \mathrm{L} ; \mathrm{pH} 7.2$ ), and $200 \mu \mathrm{L}$ of each sample was coated on triplicate sets of modified de Man, Rogosa, and Sharpe agar (MRS, Oxoid, Thermo Fisher Scientific Inc., Basingstoke, UK) and M17 agar (Oxoid), and incubated anaerobically $\left(80 \% \mathrm{~N}_{2}, 10 \% \mathrm{H}_{2}\right.$, and $\left.10 \% \mathrm{CO}_{2}\right)$ at $37^{\circ} \mathrm{C}$ for $72 \mathrm{~h}$. The MRS agar (Oxoid) was modified by adding $0.05 \%$ L-cysteine and $0.05 \mathrm{mg} / \mathrm{mL}$ mupirocin (Qingdao Hope Bio-Technology Co. Ltd., Qingdao, China; Ferraris et al., 2010). The colony morphology, size, color, transparency, and surface roughness were recorded (Holzapfel et al., 2001). Colonies were purified on the corresponding separation agar medium and incubated at $37^{\circ} \mathrm{C}$ for 72 h. Single colonies were subjected to Gram stain and cell morphology was observed under a microscope. To assay catalase activity, a single colony was mixed with a droplet of $3 \% \mathrm{H}_{2} \mathrm{O}_{2}$ (Beijing Chembase Technology Co. Ltd., Beijing, China) using an inoculating needle; a lack of bubbles indicated a negative result (Angmo et al., 2016). Gram-positive and catalase-negative strains were inoculated into liquid separation medium and incubated anaerobically at $37^{\circ} \mathrm{C}$ for $24 \mathrm{~h}$. To prepare frozen stocks, pure cultures were centrifuged at 4,000 $\times$ $g$ (M2 rotor, model T centrifuge; Regenstein Centrifuge Co., New York, NY) at room temperature $\left(22-25^{\circ} \mathrm{C}\right)$ for 10 min and washed twice with PBS; the bacterial slurry was mixed with a cryoprotective agent (10\% nonfat milk, $0.1 \%$ sodium glutamate, and $0.05 \%$ L-cysteine) and stored at $-80^{\circ} \mathrm{C}$ for long-term preservation.

\section{Identification of LAB by 16 S rRNA Gene Sequencing}

An aliquot of liquid culture of the LAB (2 mL) was centrifuged at 12,000 rpm for $1 \mathrm{~min}$, the supernatant was discarded, and the microbial biomass was collected. The DNA was extracted using a DNA Extraction Kit [Tiangen Biotech (Beijing) Co. Ltd., Beijing, China], and the concentration and purity of the genomic DNA were measured using an ND-1000 micro UV spectrophotometer (NanoDrop Technologies Inc., Wilmington, $\mathrm{DE})$. Then, $50 \mu \mathrm{L}$ of purified DNA was diluted to $100 \mathrm{ng} / \mu \mathrm{L}$ for $16 \mathrm{~S}$ rRNA amplification and sequencing using an automatic thermal cycler (MJ Research PTC-200, MJ Research Inc., Watertown, MA) with universal primers for the $16 \mathrm{~S}$ rRNA gene: 27 forward 
(5'-AGAGTTTGATCCTGGCTCAG-3') and 1495 reverse (5'-CTACGGCTACCTTGTTACGA-3'; Delbès et al., 2007). Each PCR reaction $(50 \mu \mathrm{L})$ consisted of 1.5 $\mu \mathrm{L}(10 \mu \mathrm{mol} / \mathrm{L})$ of upstream and downstream primers, $2.0 \mu \mathrm{L}$ of genomic DNA, $5.0 \mu \mathrm{L}$ of $10 \times$ buffer, $4.0 \mu \mathrm{L}$ of dNTP $(2.5 \mathrm{mmol} / \mathrm{L}), 0.5 \mu \mathrm{L}$ of Taq DNA polymerase, and $35.5 \mu \mathrm{L}$ of distilled water. Then, PCR amplification was performed as follows: predenaturation at $94^{\circ} \mathrm{C}$ for $5 \mathrm{~min}$, followed by 30 cycles $(1 \mathrm{~min}$ of denaturation at $94^{\circ} \mathrm{C}, 1 \mathrm{~min}$ of annealing at $58^{\circ} \mathrm{C}$, and $2 \mathrm{~min}$ of extension at $72^{\circ} \mathrm{C}$ ), with a final extension at $72^{\circ} \mathrm{C}$ for $10 \mathrm{~min}$. The products were held at $4^{\circ} \mathrm{C}$ to prevent degradation. The PCR products were resolved by $1 \%$ agarose gel electrophoresis and visualized on a gel imager (Beijing Sage Creation Science Co. Ltd., Beijing, China), and a DNA band of approximately 1,500 bp was obtained from all isolated strains. Sequencing was performed by Majorbio Bio-Pharm Technology Corp. (Shanghai, China). The sequences were aligned using DNA-STAR software (DNA-STAR Inc., Madison, WI). A homology alignment analysis with the nucleic acid sequences of bacteria in GenBank was performed using BLAST (http://blast.ncbi.nlm.nih.gov/Blast.cgi). A phylogenetic tree was constructed with a demarcation threshold of $>99 \%$ homology by the neighbor-joining method using MEGA version 6.0 (Tamura et al., 2007).

\section{Physiological and Biochemical Tests}

Evaluation of Growth. The strains were inoculated $(2 \%, \mathrm{vol} / \mathrm{vol})$ in MRS broth medium (Oxoid) and incubated anaerobically at $37^{\circ} \mathrm{C}$ for $30 \mathrm{~h}$. Viable bacteria were enumerated at 3 -h intervals, and a growth curve was plotted (Feng and Chang, 2012). Three independent experiments were carried out per strain.

Analysis of Physicochemical Characteristics. Bacterial colony size and morphology were evaluated by Gram stain and catalase assay. The strains were inoculated $(2 \%, \mathrm{vol} / \mathrm{vol})$ into MRS broth medium $(\mathrm{Ox}-$ oid), and their growth in air, acid ( $\mathrm{pH} 4.5)$, alkaline ( $\mathrm{pH}$ 9.6), high salts $(6.5 \% \mathrm{NaCl})$, and at a range of temperatures $\left(10,15,42\right.$, and $60^{\circ} \mathrm{C}$ for $\left.30 \mathrm{~min}\right)$ was evaluated (Angmo et al., 2016). Next, 49 types of sugars that could be fermented by the strains were identified using a carbohydrate fermentation kit (France BioMérieux Sa Company, Marcy l'Etoile, France). Three independent experiments were performed per strain (Španová et al., 2015).

\section{Preparation of Artificial Gastrointestinal Fluid}

To prepare the artificial gastric juice, $3.0 \mathrm{~g} / \mathrm{L}$ pepsin (Beijing Chembase Technology Co. Ltd.) in sterile
PBS was adjusted to $\mathrm{pH} 2.5$ using $0.1 \mathrm{~mol} / \mathrm{L} \mathrm{HCl}$ that had been sterilized by passage through a $0.22-\mu \mathrm{m}$ filter (Biosharp Biotechnology Co. Ltd., Hefei, China).

To prepare the artificial intestinal fluid, $1.0 \mathrm{~g} / \mathrm{L}$ trypsin and $1.8 \%$ bile salts (both from Beijing Chembase Technology Co. Ltd.) in sterile PBS were adjusted to $\mathrm{pH} 8.0$ with $0.1 \mathrm{~mol} / \mathrm{L} \mathrm{NaOH}$ and sterilized by filtration through a $0.22-\mu \mathrm{m}$ membrane (Biosharp Biotechnology Co. Ltd.).

\section{Evaluation of Acid and Bile Salt Tolerance}

Acid Tolerance. Eight strains were incubated anaerobically in MRS broth medium (Oxoid) at $37^{\circ} \mathrm{C}$ for $24 \mathrm{~h}$ and continuously cultured for 3 generations. After centrifugation at $4,000 \times g$ for $10 \mathrm{~min}$, the strains were collected, washed with sterile PBS, and resuspended in PBS to prepare bacterial suspensions. The bacterial suspensions were diluted, and the cell density $(0 \mathrm{~h})$ was determined by viable count. The bacterial suspensions were mixed with artificial gastric juice and incubated at $37^{\circ} \mathrm{C}$ for $3 \mathrm{~h}$. The percentage of viable bacteria was determined by plate counting. The artificial gastric juice containing bacteria, incubated for $3 \mathrm{~h}$ at $\mathrm{pH} 2.5$, was then transferred to artificial intestinal fluid and incubated anaerobically for $8 \mathrm{~h}$ at $37^{\circ} \mathrm{C}$. Finally, the survival rate (\%) was calculated by plate counting (Bao et al., 2010). The mean of 3 independent experiments was calculated:

$$
\text { Survival rate }(\%)=N_{1} / N_{0} \times 100,
$$

where $N_{0}$ is the number of viable bacteria at $0 \mathrm{~h}(\mathrm{cfu} /$ $\mathrm{mL}$ ) and $N_{1}$ is the number of viable bacteria in artificial gastrointestinal fluid at 3 and $11 \mathrm{~h}(\mathrm{cfu} / \mathrm{mL})$.

Bile Salt Tolerance. Fifty microliters of the strain preserved in the skim milk protectant was collected for activation. Strains with better tolerance to artificial gastrointestinal fluid were selected for further testing. Following incubation, the test strains were inoculated $(1.0 \%, \mathrm{vol} / \mathrm{vol})$ into MRS broth medium (Oxoid) containing bovine bile salts $(0.2 \%$ sodium thioglycolate and $0.3 \%$ oxgall; Beijing Chembase Technology Co. Ltd.); MRS broth medium (Oxoid) without bovine bile salts $(0.2 \%$ sodium thioglycolate $)$ was used as the control. The strains were incubated anaerobically at $37^{\circ} \mathrm{C}$, and the optical density (OD) at $620 \mathrm{~nm}$ was measured hourly using a UV-visible spectrophotometer (Shimadzu Corporation, Kyoto, Japan) until it had increased by $\geq 0.3$ units. The lag period was used to evaluate the ability of the strains to tolerate bile salt. Each strain was tested independently in triplicate. The lag period is defined as the difference in the time required for the 
absorbance to increase by $\geq 0.3$ units between the test and control strains (Walker and Gilliland, 1993).

\section{Statistical Analysis}

Results are expressed as mean \pm standard deviation. The statistical significance of the differences was evaluated by 1-way ANOVA using Data Processing System software version 7.05 (Zhejiang University, Hangzhou City, China). Differences were considered significant at $P<0.05$. Graphical presentations were generated by Origin software version 8.5 (OriginLab Corp., Hampton, MA).

\section{RESULTS}

\section{Isolation and Identification of $L A B$}

In total, 197 strains were isolated from 40 human colostrum samples. Sequence alignment was performed using BLAST, and species identification was performed by phylogenetic tree construction with MEGA 6.0 (Figure 1). The isolated bacteria were of the genera Staphylococcus (26.90\%), Streptococcus (37.06\%), Enterococcus (2.54\%), Lactobacillus (5.08\%), Bifidobacterium (4.06\%), Propionibacterium (1.02\%), and Actinomycetes (1.52\%; Figure 2). Among them, Lactobacillus and Bifidobacterium were abundant. The Lactobacillus species were Lactobacillus oralis (4 strains), L. plantarum (4 strains), L. gasseri (1 strain), and L. rhamnosus (1 strain). The Bifidobacterium species were Bifidobacterium dentium (2 strains), Bifidobacterium animalis (5 strains), and B. animalis ssp. lactis (1 strain). Sixteen identifiable Streptococcus species were isolated from human colostrum, including Streptococcus gordonii, Streptococcus salivarius, and Streptococcus sobrinus; the latter was the most abundant. Of the Staphylococcus species isolated from human colostrum, most were Staphylococcus epidermidis.

Based on the probiotic characteristics of Lactobacillus and Bifidobacterium strains, we screened 2 acid- and bile salt-tolerant strains. Based on their physiological and biochemical characteristics and 16S rRNA sequence analysis results, the 2 strains were identified as $B$. lactis Probio-M8 and L. rhamnosus Probio-M9, respectively.

\section{Characteristics of the Strains}

Colony Morphology. On modified MRS agar, B. lactis Probio-M8 produced convex, circular, milkywhite colonies of 1 to $2 \mathrm{~mm}$ in diameter, with complete edges and a smooth surface (Figure 3A). Gram stain showed dumbbell bacilli, regular at both ends, with many obvious nodes (Figure 3B). On MRS agar, $L$. rhamnosus Probio-M9 produced round milky-white or light-yellow colonies of 1 to $2 \mathrm{~mm}$ in diameter, with regular edges, a slightly raised center, and an opaque, smooth surface (Figure 4A). The Gram reaction was positive, and the strain was a short rod with regular ends that formed chains (Figure 4B). The morphology of the two strains was assessed using scanning electron microscopy (Figures 3C and 4C).

Physiological and Biochemical Variables. The physiological and biochemical properties of the 2 strains are shown in Tables 1 and 2. According to preliminary identification, Probio-M8 was a Bifidobacterium spp., which could grow in air and in $6.5 \% \mathrm{NaCl}$ at $\mathrm{pH} 4.5$ but not $\mathrm{pH}$ 9.6. As well, B. lactis Probio-M8 could grow at 10 to $42^{\circ} \mathrm{C}$ and use glucose, lactose, sucrose, and maltose efficiently and use ribose and D-xylose less efficiently. Probio-M9 was a Lactobacillus spp. that could grow in air and at $\mathrm{pH} 4.5$, but not at $\mathrm{pH} 9.6$ or in $6.5 \%$ $\mathrm{NaCl}$. As well, L. rhamnosus Probio-M9 could grow at $42^{\circ} \mathrm{C}$ but not at low temperatures; it could use glucose, fructose, maltose, lactose, cottonseed sugar, xylose, melisaccharide, and other carbohydrates.

Acid Tolerance. Probiotics such as Lactobacillus and Bifidobacterium enter the mouth, pass through the acidic environment of the stomach, and colonize the gut (Tuo et al., 2012). We evaluated the acid tolerance of 18 Lactobacillus and Bifidobacterium strains at $\mathrm{pH} 2.5$ for $3 \mathrm{~h}$, among which 8 strains showed good tolerance. Eight strains were subjected to transport tolerance testing in artificial gastric juice at $\mathrm{pH} 2.5$ and in artificial intestinal juice at $\mathrm{pH}$ 8.0. As shown in Table 3, B. lactis BB12, L. rhamnosus GG, and L. plantarum P-8 were used as controls. In the simulated gastrointestinal environment, only B. lactis Probio-M8 and L. rhamnosus Probio-M9 showed high tolerance (survival rate $>80 \%$ ). The strain B. lactis Probio-M8 was exposed to artificial gastric juice at $\mathrm{pH} 2.5$ for 3 $\mathrm{h}$ (survival rate $85.38 \%$ ) and artificial intestinal juice at $\mathrm{pH} 8.0$ for $8 \mathrm{~h}$ (survival rate $97.25 \%$ ); its survival rate was superior to that of the control strain B. lactis BB12. The strain L. rhamnosus Probio-M9 was exposed to artificial gastric juice at $\mathrm{pH} 2.5$ for $3 \mathrm{~h}$ (survival rate $83.72 \%$ ) and artificial intestinal juice at $\mathrm{pH} 8.0$ for $8 \mathrm{~h}$ (survival rate $78.33 \%$ ); its survival rate was superior to that of the control strain L. rhamnosus GG. The survival rates of the other 6 strains ranged from 6.52 to $38.06 \%$ in artificial gastric juice at $\mathrm{pH} 2.5$ for $3 \mathrm{~h}$, and 1 to $31.59 \%$ in artificial intestinal juice at $\mathrm{pH} 8.0$ for $8 \mathrm{~h}$. Bifidobacterium animalis GSL-1 and L. plantarum LN3-1 showed little tolerance to artificial intestinal juice. As well, B. lactis Probio-M8 and L. rhamnosus ProbioM9 were tolerant to gastrointestinal juices in continu- 


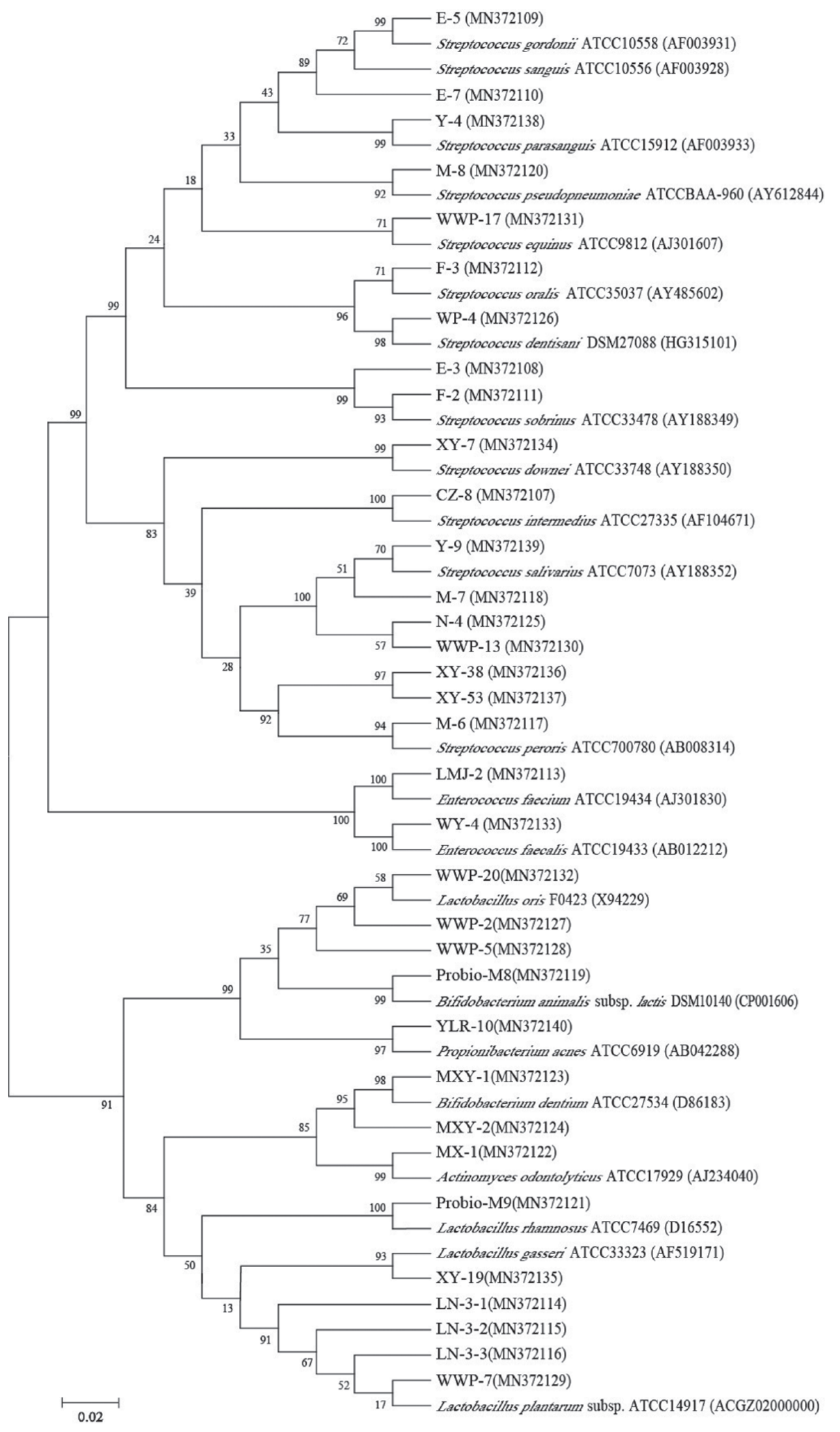

Figure 1. The phylogenetic tree based on $16 \mathrm{~S}$ rRNA genes of isolates and type strains. 


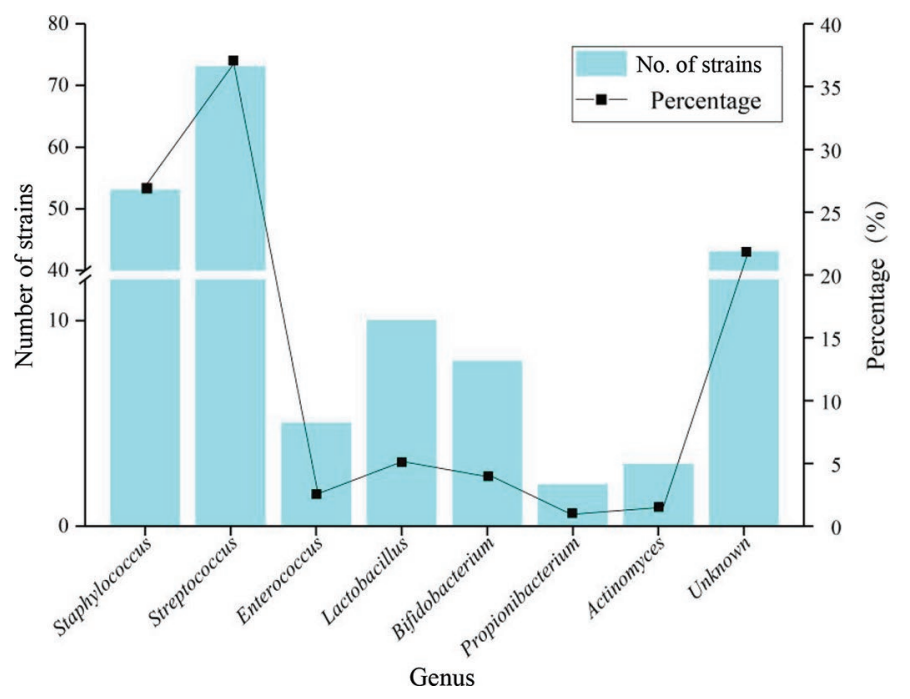

Figure 2. Bacterial genus distribution of 197 strains from $40 \mathrm{hu}-$ man colostrum samples.

ous culture and so could survive passage through the stomach to reach the intestine.

Bile Salt Tolerance. The tolerance of the strains to bile salts was evaluated by lag period. When the OD $(600 \mathrm{~nm})$ value of each strain reached 0.3 units greater than the value at $0 \mathrm{~h}$, the measurement was stopped immediately; the time was then recorded. The time difference for the same strain between the test and control groups was compared and recorded as the lag period. The growth of the control and test strains was inhibited to different degrees in MRS broth medium containing $0.3 \%$ bile salts, and all showed good tolerance (lag times: $0.95,1.98,1.87$, and $2.10 \mathrm{~h}$, respectively). In the presence of $0.3 \%$ bile salts, $B$. lactis Probio-M8 showed greater tolerance than the 2 control strains $(P<0.05) ;$ L. rhamnosus Probio-M9 and $B$. lactis BB12 showed similar levels of bile salt tolerance, which were greater than that of $L$. rhamnosus GG ( $P$
$<0.05$ ) (Table 4). Therefore, B. lactis Probio-M8 and L. rhamnosus Probio-M9 could survive in the intestinal tract and reduce oxidative stress.

Growth. Bifidobacterium lactis Probio-M8 (1.725 × $10^{7} \mathrm{cfu} / \mathrm{mL}$ ) was inoculated into modified MRS broth medium, continuously cultured at $37^{\circ} \mathrm{C}$ for $30 \mathrm{~h}$, and entered logarithmic growth after $6 \mathrm{~h}$. The viable count peaked at $2.075 \times 10^{9} \mathrm{cfu} / \mathrm{mL}$ at $18 \mathrm{~h}$, and then slightly decreased to a plateau (Figure 5A). Lactobacillus rhamnosus Probio-M9 $\left(1.555 \times 10^{7} \mathrm{cfu} / \mathrm{mL}\right)$ was inoculated into modified MRS broth medium and underwent logarithmic growth at 3 to $18 \mathrm{~h}$. The viable count peaked at $2.967 \times 10^{9} \mathrm{cfu} / \mathrm{mL}$ at $21 \mathrm{~h}$ and then slightly decreased to a plateau (Figure 5B).

\section{DISCUSSION}

Bacteria are present in the breast milk of healthy lactating women. Among them, the genera Staphylococcus, Streptococcus, and Propionibacterium are core members of the human milk microbiota; these genera appear to be common in healthy breast milk, irrespective of maternal and infant characteristics (Hunt et al., 2011; Jiménez et al., 2015; Sakwinska et al., 2016). Staphylococcus and Propionibacterium can also be isolated from the skin and may prevent the host from being colonized by more dangerous pathogens, such as Staphylococcus aureus (Iwase et al., 2010). The presence of potentially beneficial bacteria in human milk (e.g., Lactobacillus and Bifidobacterium species) is frequently reported (Martín et al., 2003, 2009; Abrahamsson et al., 2009; Solís et al., 2010; Arboleya et al., 2011; Murphy et al., 2017), although these species are not detected in all samples and populations studied; moreover, they usually represent a minority, albeit an important one, of the bacterial populations detected (Chen et al., 2018). For example, Bifidobacterium and Lactobacillus represented $1.70 \%$ and $0.40 \%$ of all isolated bacteria. The

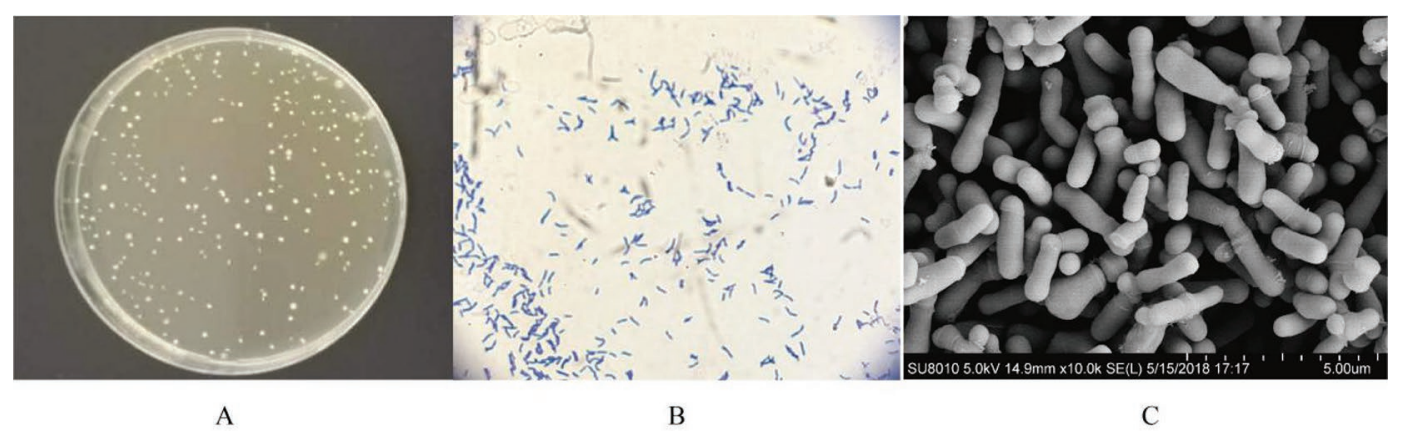

Figure 3. Morphologic observation of Bifidobacterium lactis Probio-M8. (A) Colony morphology; (B) Gram stain; (C) scanning electron microscopy. Morphology of the bacteria was observed under an optical microscope $\times 1,000$ and under a scanning electron microscope $\times 10,000$. 


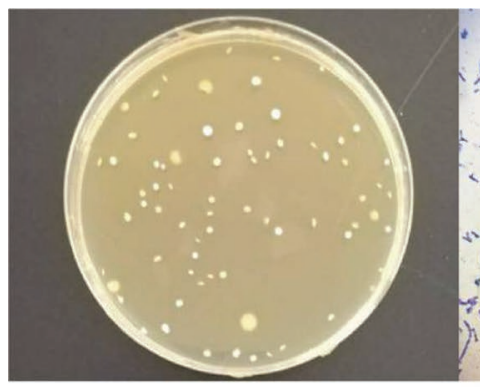

A

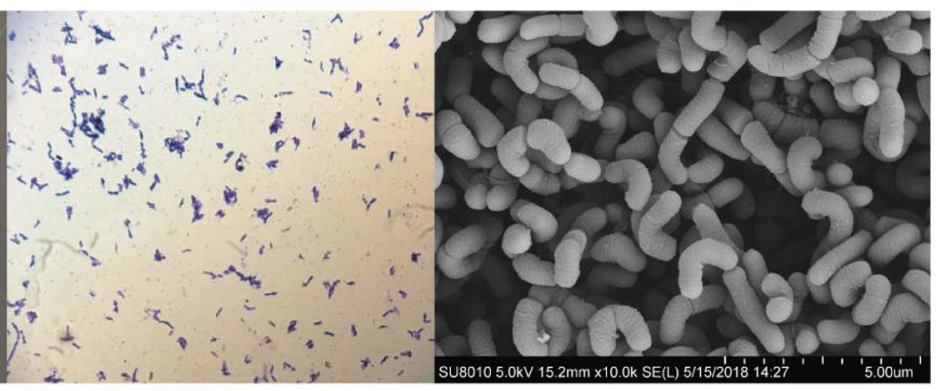

B

C

Figure 4. Morphologic observation of Lactobacillus rhamnosus Probio-M9. (A) Colony morphology; (B) Gram stain; (C) scanning electron microscopy. Morphology of the bacteria was observed under an optical microscope $\times 1,000$ and under a scanning electron microscope $\times 10,000$.

197 strains of bacteria isolated in this study included Staphylococcus, Streptococcus, Enterococcus, and other species; the proportions of Bifidobacterium (4.06\%) and Lactobacillus $(5.08 \%)$ were small. Therefore, we confirmed that Streptococcus and Staphylococcus predominate in human breast milk, and that Bifidobacterium and Lactobacillus are present at lower levels. The infant intestinal tract progresses from sterility at birth to extremely dense colonization at the end of the first year of life. By 1 yr of age, the infant microflora retains its uniqueness but has converged toward a profile characteristic of the adult gastrointestinal tract. Breastfeeding has a profound influence on the gut microbiota; in particular, it is associated with the presence of Bifidobacterium. This has prompted international organizations to recommend exclusive breastfeeding during the first 6 mo of life (World Health Organization, 2003). Bifidobacterium was initially isolated from the feces of a breastfed infant by Dr. Tidder of the Pasteur Institute in France (Zhang, 2012). It resides mainly in the human gastrointestinal tract, along which its abundance varies

Table 1. Physiological and biochemical variables of Bifidobacterium lactis Probio-M8 and Lactobacillus rhamnosus Probio-M9 ${ }^{1}$

\begin{tabular}{lll}
\hline & $\begin{array}{l}\text { B. lactis } \\
\text { Probio-M8 }\end{array}$ & $\begin{array}{l}\text { L. rhamnosus } \\
\text { Probio-M9 }\end{array}$ \\
\hline Cell morphology & Rod & Rod \\
Gram stain & + & + \\
Motility & - & - \\
Spore formation & - & - \\
Contact enzyme & - & - \\
Aerobic growth & + & + \\
$6.5 \%$ NaCl growth & + & - \\
pH 4.5 growth & + & + \\
$\mathrm{pH} 9.6$ growth & - & - \\
$10^{\circ} \mathrm{C}$ growth & + & - \\
$15^{\circ} \mathrm{C}$ growth & + & + \\
$42^{\circ} \mathrm{C}$ growth & + & - \\
$60^{\circ} \mathrm{C}, 30$ min growth & - & \\
\hline
\end{tabular}

${ }^{1}+$, positive; - , negative. markedly and becomes dominant at d 6 to 8 after birth (Cheikhyoussef et al., 2009). Bifidobacterium spp. are found equally frequently in breastfed infants (Benno et al., 1984; Martín et al., 2009; Chen et al., 2016) and predominate in the intestinal microflora of children; Lactobacillus spp. are similarly highly represented, including L. rhamnosus (Adlerberth and Wold, 2009), which was first isolated from the intestinal flora of a healthy human by Gorbach and Goldin in the United States, and so is also known as L. rhamnosus GG. It has been isolated from human feces ( $\mathrm{Gu}$ et al., 2008; Muñoz-Quezada et al., 2013) and human intestine (Chen et al., 2014), as well as from cheese (Morales et al., 2011). In 2017, a thorough screening of L. rhamnosus strains from breast milk was performed to evaluate their potential use in probiotic products, and the authors found that cell-free culture supernatants of $L$. rhamnosus strains had a significant anticancer effect on HeLa cervical cancer cells via induction of cytotoxicity and apoptosis (Riaz Rajoka et al., 2017). Lactobacillus has a high intestinal adhesion rate and readily colonizes the intestinal tract; it can modulate the intestinal flora, prevent and treat diarrhea, prevent allergy, improve immunity, and exhibit anticancer activity (Björkstén, 2004; Österlund et al., 2007; Andrade and Borges, 2009; Hojsak et al., 2010; Riaz Rajoka et al., 2018). In recent years, scientists in China have begun to study probiotics in breast milk, with the aim of evaluating the effect of microbes in breast milk on the intestinal health of infants. Therefore, we conducted a preliminary evaluation of the potential probiotic characteristics of Bifidobacterium and Lactobacillus isolated from breast milk, in terms of survival in the host gastrointestinal tract and resistance to bile salts, to address the scarcity of probiotics originating from breast milk.

The ability of probiotics to survive in high bile salt concentrations and at a low $\mathrm{pH}$ are important features for successful passage through the gastrointestinal tract (Patel et al., 2014; Mandal et al., 2016). The pH of 
Table 2. Carbohydrate fermentation by Bifidobacterium lactis Probio-M8 and Lactobacillus rhamnosus Probio-M9 ${ }^{1}$

\begin{tabular}{|c|c|c|c|}
\hline $\begin{array}{l}\text { Serial } \\
\text { number }\end{array}$ & $\begin{array}{l}\text { Sugar } \\
\text { alcohol }\end{array}$ & Probio-M8 & Probio-M9 \\
\hline 0 & Contrast & - & - \\
\hline 1 & Glycerol & - & - \\
\hline 2 & Erythritol & - & - \\
\hline 3 & D-Arabinose & - & + \\
\hline 4 & L-Arabinose & - & + \\
\hline 5 & D-Ribose & + & + \\
\hline 6 & D-Xylose & + & - \\
\hline 7 & L-Xylose & - & - \\
\hline 8 & D-Adonitol & - & - \\
\hline 9 & $\begin{array}{l}\text { Methyl- } \beta \text { D- } \\
\text { xylopyranoside }\end{array}$ & - & - \\
\hline 10 & D-Galactose & - & + \\
\hline 11 & D-Glucose & + & + \\
\hline 12 & D-Fructose & - & + \\
\hline 13 & D-Mannose & - & + \\
\hline 14 & L-Sorbose & + & + \\
\hline 15 & L-Rhamnose & - & + \\
\hline 16 & Dulcitol & - & - \\
\hline 17 & Inositol & - & - \\
\hline 18 & D-Mannitol & - & + \\
\hline 19 & D-Sorbitol & - & + \\
\hline 20 & $\begin{array}{l}\text { Methyl- } \alpha \text { D- } \\
\text { mannopyranoside }\end{array}$ & - & - \\
\hline 21 & $\begin{array}{l}\text { Methyl- } \alpha \text { D- } \\
\text { glucopyranoside }\end{array}$ & - & + \\
\hline 22 & $N$-Acetylglucosamine & - & + \\
\hline 23 & Amygdaline & - & + \\
\hline 24 & Arbutine & - & + \\
\hline 25 & Esculine ferric citrate & + & + \\
\hline 26 & Salicine & - & + \\
\hline 27 & D-Cellobiose & - & + \\
\hline 28 & D-Maltose & + & + \\
\hline 29 & D-Lactose (bovine origin) & + & + \\
\hline 30 & D-Melibiose & + & - \\
\hline 31 & D-Saccharose & + & + \\
\hline 32 & D-Trehalose & - & + \\
\hline 33 & Inuline & - & + \\
\hline 34 & D-Melezitose & - & + \\
\hline 35 & D-Raffinose & + & - \\
\hline 36 & Starch & - & - \\
\hline 37 & Glycogen & - & - \\
\hline 38 & Xylitol & - & - \\
\hline 39 & Gentiobiose & - & + \\
\hline 40 & D-Turanose & - & + \\
\hline 41 & D-Lyxose & - & - \\
\hline 42 & D-Tagatose & - & + \\
\hline 43 & D-Fucose & - & - \\
\hline 44 & L-Fucose & - & - \\
\hline 45 & D-Arabitol & - & - \\
\hline 46 & L-Arabitol & + & - \\
\hline 47 & Potassium gluconate & - & + \\
\hline 48 & $\begin{array}{l}\text { Potassium } \\
\text { 2-cetogluconate }\end{array}$ & + & + \\
\hline 49 & $\begin{array}{l}\text { Potassium } \\
\text { 2-cetogluconate }\end{array}$ & - & - \\
\hline
\end{tabular}

${ }^{1}+$, positive; -, negative. Serial numbers were provided in the carbohydrate fermentation kit (bioMérieux SA, Marcy l'Étoile, France).

human gastric juice is typically around 3.0, and the digestion time is 1 to $3 \mathrm{~h}$. The survival rate of $\mathrm{LAB}$ in artificial gastric juice for $3 \mathrm{~h}$ is evaluated to screen for tolerant strains (Chen et al., 2015). In the pres- ent study, 10 strains of Lactobacillus and 8 strains of Bifidobacterium were screened in terms of their ability to tolerate gastric acid. Eight strains were resistant to artificial gastric juice at $\mathrm{pH} 2.5$, including 6 of Bifidobacterium, 1 of L. rhamnosus, and 1 of L. plantarum. At least an $80 \%$ survival rate in gastric juice at $\mathrm{pH} 2.5$ for $3 \mathrm{~h}$ is the standard for identifying potentially probiotic organisms (Liu et al., 2007; Nawaz et al., 2011). Compared with B. lactis BB12, L. rhamnosus GG, and L. plantarum P-8 control strains, B. lactis Probio-M8 and L. rhamnosus Probio-M9 showed similar survival rates and greater tolerance. The survival rates of $L$. plantarum LN-3-1 and B. animalis GRS-1 exposed to gastric juice for $3 \mathrm{~h}$ were $<40 \%$, half the rates of $B$. lactis M8 and L. rhamnosus Probio-M9; the other test strains showed survival rates of $<10 \%$. The test strains also tolerated artificial intestinal juice at $\mathrm{pH} 8.0$ for $8 \mathrm{~h}$. The survival rates of $B$. lactis Probio-M8 and $L$. rhamnosus Probio-M9 were $>75 \%$ after exposure to artificial intestinal juice at $\mathrm{pH} 8.0$ for $4 \mathrm{~h}$; in contrast, the survival rates of the other strains decreased slightly. Surprisingly, the survival rate of B. lactis Probio-M8 was $97.25 \%$ after exposure to extreme alkalinity. The survival rate of $B$. lactis Probio-M8 in the gastrointestinal environment was higher than the survival rates of previously reported strains, such as Bifidobacterium spp., L. rhamnosus, and Lactobacillus casei (Fang, 2012; Tulumoglu et al., 2013; Tuo et al., 2013; Manini et al., 2016). Another study found that 7 strains of Lactobacillus isolated from breast milk showed strong acid resistance, with survival rates of $>80 \%$ at $\mathrm{pH} 2.0$ to 3.0 followed by transfer to bile at a concentration of $1.0 \%$ (wt/vol); indeed, the survival rate of L. rhamnosus was $80 \%$ and that of $L$. casei was $57 \%$ (Riaz Rajoka et al., $2017,2018)$. These rates were significantly higher than those observed in a previous study of L. rhamnosus IMC501 and Lactobacillus paracasei IMC502 using a bile concentration of $0.3 \%$ (mass/vol) (Verdenelli et al., 2009). However, compared with the artificial intestinal fluid bile salt concentration of $1.8 \%$ in the present study, the concentration in the previous study was insufficient. The bile salt concentration in the intestinal tract ranges from 1.5 to $2.0 \%$ (wt/vol) during the first hour of digestion, and then decreases to $0.3 \%$ (wt/vol; Wang et al., 2014). We selected artificial intestinal fluid with a higher bile concentration to better determine the tolerance of the strains, and B. lactis Probio-M8 and $L$. rhamnosus Probio-M9 showed a high level of tolerance to bile acids. Normally, ingested probiotics are buffered by food or some other medium in the stomach, and so are not likely to be exposed to extreme $\mathrm{pH}$, except under rare circumstances, such as calcinosis and acid indigestion. Our results indicated that B. lactis ProbioM8 and L. rhamnosus Probio-M9 from human breast 
Table 3. Survival of Lactobacillus and Bifidobacterium strains in artificial gastric and intestinal juices

\begin{tabular}{|c|c|c|c|c|c|c|c|}
\hline \multirow[b]{2}{*}{ Strain } & \multicolumn{3}{|c|}{ Artificial gastric juice at $\mathrm{pH} 2.5$} & \multicolumn{4}{|c|}{ Artificial intestinal juice at $\mathrm{pH} 8.0$} \\
\hline & $0 \mathrm{~h}$ & $3 \mathrm{~h}$ & $\frac{\text { Survival rate }(\%)}{3 \mathrm{~h} / 0 \mathrm{~h}}$ & $4 \mathrm{~h}$ & $8 \mathrm{~h}$ & $7 \mathrm{~h} / 3 \mathrm{~h}$ & $11 \mathrm{~h} / 3 \mathrm{~h}$ \\
\hline \multicolumn{8}{|l|}{ Bifidobacterium } \\
\hline BB12 (control) & $4.10 \times 10^{9}$ & $3.53 \times 10^{9}$ & 86.10 & $2.67 \times 10^{9}$ & $2.97 \times 10^{9}$ & 75.64 & 84.14 \\
\hline LN-1 & $5.32 \times 10^{9}$ & $3.64 \times 10^{8}$ & 6.84 & $1.01 \times 10^{8}$ & $1.15 \times 10^{8}$ & 27.75 & 31.59 \\
\hline GRS-1 & $4.15 \times 10^{9}$ & $6.95 \times 10^{8}$ & 16.75 & $1.96 \times 10^{8}$ & $1.20 \times 10^{8}$ & 28.20 & 17.27 \\
\hline Probio-M8 & $3.83 \times 10^{9}$ & $3.27 \times 10^{9}$ & 85.38 & $3.27 \times 10^{9}$ & $3.18 \times 10^{9}$ & 100.00 & 97.25 \\
\hline \multicolumn{8}{|l|}{ Lactobacillus } \\
\hline GG (control) & $8.73 \times 10^{8}$ & $7.55 \times 10^{8}$ & 86.48 & $4.90 \times 10^{8}$ & $5.20 \times 10^{8}$ & 64.90 & 68.87 \\
\hline Probio-M9 & $4.30 \times 10^{8}$ & $3.60 \times 10^{8}$ & 83.72 & $1.96 \times 10^{8}$ & $2.82 \times 10^{8}$ & 76.67 & 78.33 \\
\hline P-8 (control) & $3.45 \times 10^{9}$ & $3.04 \times 10^{9}$ & 88.12 & $2.33 \times 10^{9}$ & $2.20 \times 10^{9}$ & 76.64 & 72.37 \\
\hline
\end{tabular}

milk could transit through the stomach at $\mathrm{pH} 2.5$ and reach the intestinal tract to exert a beneficial effect.

Bile salts are sodium or potassium salts formed by the combination of glycine or taurine and bile acid (Tanaka et al., 1999); these salts play important roles in the digestion and absorption of fat. The high osmotic pressure and surfactant activity of bile salts disrupt phospholipids and proteins in the bacterial cell membrane, altering the membrane permeability and causing damage or death (Begley et al., 2005). Resistance to cholic acid is an essential component of screening for probiotics. Generally, the concentration of bile salts fluctuates within the range of 0.03 to $0.3 \%$; we used the highest concentration in the present study. In the presence of $0.3 \%$ bile salts, the OD of B. lactis Probio-M8 and L. rhamnosus Probio-M9 increased by 0.3 units at 0.95 and $1.87 \mathrm{~h}$, respectively. In the absence of bile salts, the OD of $L$. rhamnosus GG increased by 0.3 units at $4.07 \mathrm{~h}$, followed by B. lactis BB12 and L. rhamnosus Probio-M9. The OD of B. lactis Probio-M8 increased by 0.3 units at $6.50 \pm 0.02 \mathrm{~h}$, more than $2 \mathrm{~h}$ later than the other strains. However, in the presence of bile salts, the OD of B. lactis M8 increased by 0.3 units at $1 \mathrm{~h}$, so this strain showed the highest tolerance to bile salts $(P$ $<0.05$ ). Therefore, B. lactis Probio-M8 and L. rhamnosus Probio-M9 could survive in the intestinal tract. A previous study isolated B. animalis ssp. lactis BZ11 from Guizhou Xiang pig feces and reported that the strain had high tolerance to oxygen, acid, and cholate. In particular, the survival rate was $92.65 \%$ compared with bacteria cultured in a medium that did not include bile salts (Zhu et al., 2017). This finding may have been due to the isolation of the selected strains from the animal intestinal tract. Another study reported that L. rhamnosus Z5 exhibited a survival rate of $76.14 \%$ after incubation for $6 \mathrm{~h}$ in $0.15 \%$ bile salts; however, its growth was severely inhibited at a higher concentration of bile salts (Gao et al., 2017). A further study reported that the growth of $L$. rhamnosus GG was completely inhibited by bile salts at $0.15 \%$ (Zhao et al., 2016). This was consistent with our finding that $L$. rhamnosus GG showed the longest delay period of the strains tested. The mechanisms of tolerance to low concentrations of bile salts by LAB have been reported. For example,

Table 4. Tolerance of Lactobacillus and Bifidobacterium strains to $0.3 \%$ bile salts in broth medium (lag time) $)^{1}$

\begin{tabular}{lccc}
\hline & \multicolumn{2}{c}{ Time $(\mathrm{h})$ to increase absorbance by 0.3 units at $620 \mathrm{~nm}^{2}$} & \\
\cline { 2 - 3 } Strain & MRS without bile salts & MRS with $0.3 \%$ bile salts & Lag time $(\mathrm{h})$ \\
\hline Bifidobacterium & $6.50 \pm 0.02^{\mathrm{a}}$ & $7.45 \pm 0.05^{\mathrm{a}}$ & $0.95 \pm 0.03^{\mathrm{c}}$ \\
Probio-M8 & $4.30 \pm 0.04^{\mathrm{bc}}$ & $6.28 \pm 0.01^{\mathrm{b}}$ & $1.98 \pm 0.03^{\mathrm{ab}}$ \\
BB12 & & & \\
Lactobacillus & $4.37 \pm 0.08^{\mathrm{b}}$ & $6.24 \pm 0.12^{\mathrm{b}}$ & $1.87 \pm 0.04^{\mathrm{b}}$ \\
Probio-M9 & $4.07 \pm 0.16^{\mathrm{c}}$ & $6.17 \pm 0.09^{\mathrm{b}}$ & $2.10 \pm 0.07^{\mathrm{a}}$ \\
GG & & \\
\hline
\end{tabular}

${ }^{a-c}$ Values in a column with different superscript letters are significantly different $(P<0.05)$.

${ }^{1}$ Data are mean $\pm \mathrm{SD}$ of triplicate experiments.

${ }^{2} \mathrm{MRS}=$ de Man, Rogosa, and Sharpe medium. 
(A)

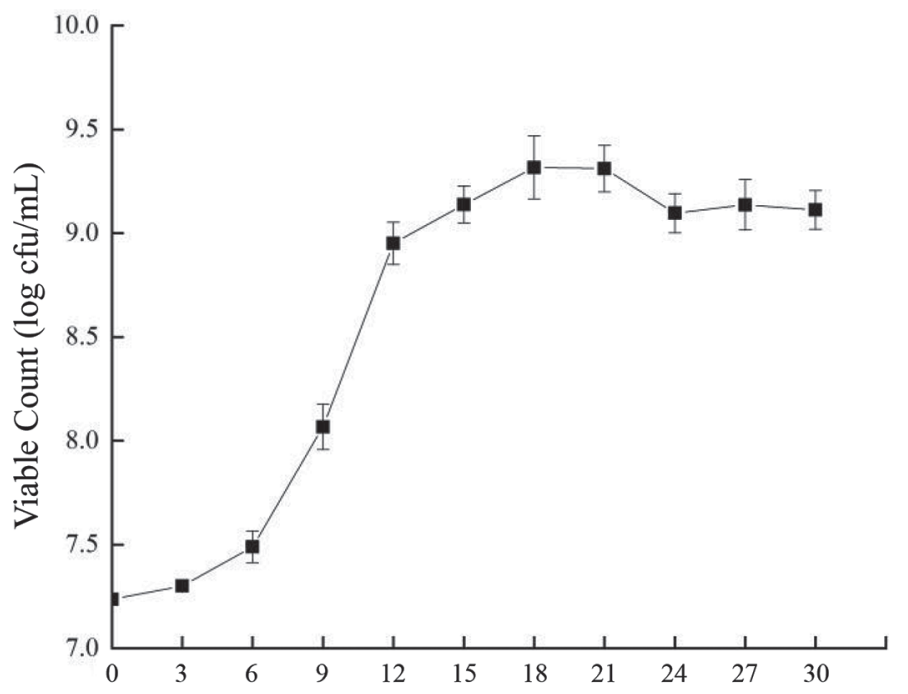

(B)

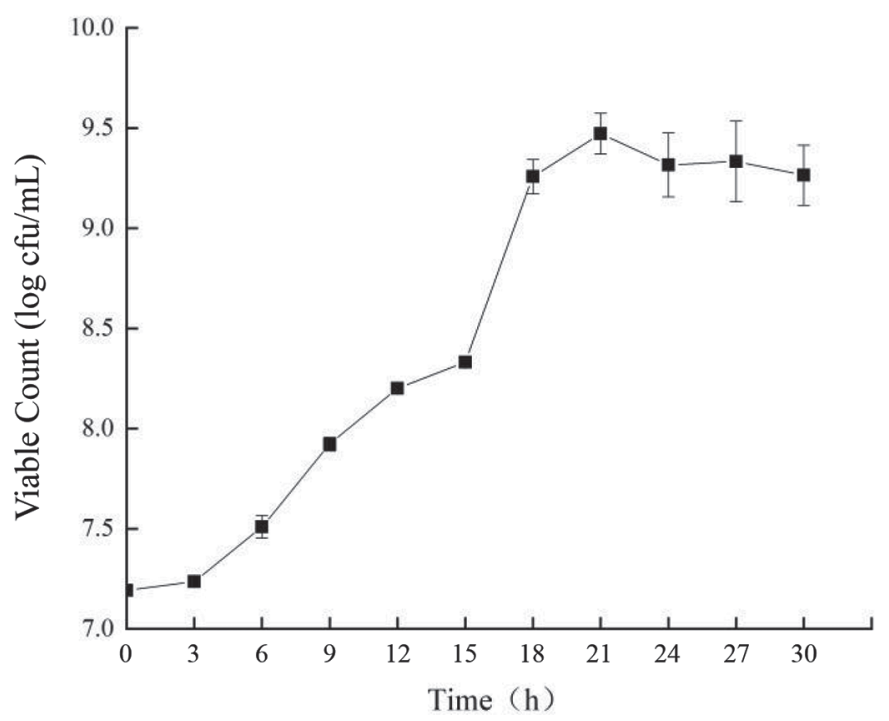

Figure 5. Growth curves of strains (A) Bifidobacterium lactis Probio-M8; (B) Lactobacillus rhamnosus Probio-M9. Results are expressed as mean $\pm \mathrm{SD}$.

biliary salt hydrolase converts toxic primary bile salts to less toxic secondary bile salts, promoting the survival of LAB in the gastrointestinal tract. The bile saltwater lyase activity of Bifidobacterium is greater than that of Lactobacillus, and strains isolated from the intestinal tract generally have higher bile saltwater lyase activity than those isolated from natural habitats (Bustos et al., 2012).
Advances in the assessment of early hosts and breastfeeding microbes suggest that early colonization of the infant intestine by milk bacteria may promote disease prevention in children and have a positive effect on health in later life. It has been suggested that the microorganisms in breast milk aid in the maintenance of human health. However, studies in currently available strains originating from human milk are scare. In particular, in China few reports are available concerning the screening of probiotic strains on L. rhamnosus and B. lactis from human milk. Moreover, resistance to human gastric transit is an important selection criterion for probiotic bacteria. We tested LAB isolated from human milk samples and evaluated their healthpromoting potential in an in vitro model. As well, most probiotics strains used currently in China are imported from Europe and the United States, and not enough evidence is available to determine whether these strains are suitable for Chinese intestines and body types. In China, research on LAB and probiotics from human milk started late and lacked sufficient knowledge and strains. Here we provide 2 active probiotic strains of Probio-M8 and Probio-M9 isolated from human milk, These strains, with independent intellectual property rights in China, may be more suitable for Chinese people and other Asians. Our research team has also carried out a series of studies of Probio-M8/-M9, including a safety evaluation, animal experiments, and whole-genome sequencing. We found that L. rhamnosus Probio-M9 significantly improved the curative effect of tumor immunotherapy (PD-1) and inhibited the development of breast cancer in mice. More research will follow.

\section{CONCLUSIONS}

Lactic acid bacteria from human milk are important probiotics used frequently in related studies. By $16 \mathrm{~S}$ rRNA gene sequencing and phylogenetic analysis, 197 strains were isolated and identified from 40 samples of human colostrum. These strains comprised 5 LAB genera and 2 other genera, as well as 10 Lactobacillus strains and 8 Bifidobacterium strains. We evaluated the ability of these strains to tolerate artificial gastric and intestinal juice in vitro to assess their ability to survive transit through the digestive tract. Eight of the 18 strains (44.44\%) grew well at $\mathrm{pH} 2.5$ for $3 \mathrm{~h}$. Two strains showed tolerance to gastric acid and bile salts. Of these 2 strains, B. lactis Probio-M8 exhibited the greatest tolerance to bile salts and artificial gastric and intestinal fluid. In summary, we isolated 2 novel strains with potential probiotic characteristics, 
and our work will facilitate the identification of further probiotic strains for use in the food and pharmaceutical industries.

\section{ACKNOWLEDGMENTS}

This work was supported by the Food Science and Technology Fund of the Chinese Institute of Food Science and the Technology-Youth Fund of Ketuo Hengtong Probiotics Research (No. 2018 ktjj01). All authors have declared that they have no conflicts of interest in publishing this research.

\section{REFERENCES}

Abrahamsson, T. R., G. Sinkiewicz, T. Jakobsson, M. Fredrikson, and B. Björkstén. 2009. Probiotic Lactobacilli in breast milk and infant stool in relation to oral intake during the first year of life. J. Pediatr. Gastroenterol. Nutr. 49:349-354. https://doi.org/10.1097/ MPG.0b013e31818f091b.

Adlerberth, I., and A. E. Wold. 2009. Establishment of the gut microbiota in Western infants. Acta Paediatrica. 98:229-238.

Amezcua López, J. A., E. García Morales, J. R. Solís Pacheco, J. A. Gutiérrez Padilla, A. S. M. Zepeda Morales, E. Angulo Castellanos, M. López Mincitar, K. F. Flores Arévalo, and B. R. Aguilar Uscanga. 2019. Influence of the diet of Mexican women on the nutritional quality and the presence of beneficial microorganisms in human milk. Nutr. Hosp. 36:1139-1149.

Andrade, S., and N. Borges. 2009. Effect of fermented milk containing Lactobacillus acidophilus and Bifidobacterium longum on plasma lipids of women with normal or moderately elevated cholesterol. J. Dairy Res. 76:469-474. https://doi.org/10.1017/ S0022029909990173.

Angmo, K., A. Kumari, Savitri, and T. C. Bhalla. 2016. Probiotic characterization of lactic acid bacteria isolated from fermented foods and beverage of Ladakh. Lebensm. Wiss. Technol. 66:428 435. https://doi.org/10.1016/j.lwt.2015.10.057.

Arboleya, S., P. Ruas-Madiedo, A. Margolles, G. Solís, S. Salminen, C. G. de los Reyes-Gavilán, and M. Gueimonde. 2011. Characterization and in vitro properties of potentially probiotic Bifidobacterium strains isolated from breast-milk. Int. J. Food Microbiol. 149:28-36. https://doi.org/10.1016/j.ijfoodmicro.2010.10.036.

Arici, M., B. Bilgin, O. Sagdic, and C. Ozdemir. 2004. Some characteristics of Lactobacillus isolates from infant faeces. Food Microbiol. 21:19-24. https://doi.org/10.1016/S0740-0020(03)00044-3.

Arroyo, R., V. Martín, A. Maldonado, E. Jiménez, L. Fernández, and J. M. Rodríguez. 2010. Treatment of infectious mastitis during lactation: Antibiotics versus oral administration of lactobacilli isolated from breast milk. Clin. Infect. Dis. 50:1551-1558. https://doi .org/10.1086/652763.

Bao, Y., Y. Zhang, Y. Zhang, Y. Liu, S. Wang, X. Dong, Y. Wang, and H. Zhang. 2010. Screening of potential probiotic properties of Lactobacillus fermentum isolated from traditional dairy products. Food Control 21:695-701. https://doi.org/10.1016/j.foodcont.2009 .10 .010 .

Begley, M., C. G. M. Gahan, and C. Hill. 2005. The interaction between bacteria and bile. FEMS Microbiol. Rev. 29:625-651. https: //doi.org/10.1016/j.femsre.2004.09.003.

Benno, Y., K. Sawada, and T. Mitsuoka. 1984. The intestinal microflora of infants: Composition of fecal flora in breast-fed and bottlefed infants. Microbiol. Immunol. 28:975-986. https://doi.org/10 $.1111 /$ j.1348-0421.1984.tb00754.x.

Björkstén, B. 2004. Effects of intestinal microflora and the environment on the development of asthma and allergy. Springer Semin. Immunopathol. 25:257-270. https://doi.org/10.1007/s00281-003 $-0142-2$.
Bode, L. 2012. Human milk oligosaccharides: Every baby needs a sugar mama. Glycobiology 22:1147-1162. https://doi.org/10.1093/ glycob/cws074.

Bustos, A. Y., L. Saavedra, G. F. de Valdez, R. R. Raya, and M. P. Taranto. 2012. Relationship between bile salt hydrolase activity changes in the internal $\mathrm{pH}$ and tolerance to bile acids in lactic acid bacteria. Biotechnol. Lett. 34:1511-1518. https://doi.org/10.1007/ s10529-012-0932-5.

Cheikhyoussef, A., N. Pogori, H. Q. Chen, F. W. Tian, W. Chen, J. Tang, and H. Zhang. 2009. Antimicrobial activity and partial characterization of bacteriocin-like inhibitory substances (BLIS) produced by Bifidobacterium infantis BCRC 14602. Food Control 20:553-559. https://doi.org/10.1016/j.foodcont.2008.08.003.

Chen, D. W., F. X. Guo, R. X. Gu, D. H. Zou, H. Q. Zhao, and H. X. Qu. 2014. Screening and functional study of human blood lipidlowering lactic acid bacteria. Shipin Yu Fajiao Gongye 40:23-29. [in Chinese]

Chen, P. W., Y. L. Lin, and M. S. Huang. 2018. Profiles of commensal and opportunistic bacteria in human milk from healthy donors in Taiwan. J. Food Drug Anal. 26:1235-1244. https://doi.org/10 $.1016 / j . j f d a .2018 .03 .004$

Chen, X. Y., J. Li, X. Zhao, Y. Qian, L. H. Chen, J. Chen, and H. Y. Suo. 2015. In vitro screening of lactic acid bacteria with probiotic properties from traditional fermented Yak yogurt. Shipin Yu Fajiao Gongye 42:85-90. [in Chinese]

Chen, Z., W. G. Pan, W. Y. Xian, H. Cheng, J. X. Zheng, Q. H. Hu, Z. J. Yu, and Q. W. Deng. 2016. Identification of infantile diarrhea caused by breast milk-transmitted Staphylococcus aureus infection. Curr. Microbiol. 73:498-502. https://doi.org/10.1007/s00284-016 $-1088-7$.

Chiu, Y. H., J. J. Tsai, S. L. Lin, C. Chotirosvakin, and M. Y. Lin. 2014. Characterisation of bifidobacteria with immunomodulatory properties isolated from human breast milk. J. Funct. Foods 7:700-708. https://doi.org/10.1016/j.jff.2013.12.015.

Delbès, C., L. Ali-Mandjee, and M. C. Montel. 2007. Monitoring bacterial communities in raw milk and cheese by culture-dependent and -independent 16S rRNA gene-based analyses. Appl. Environ. Microbiol. 73:1882-1891. https://doi.org/10.1128/AEM.01716-06.

Escribano, E., L. Moles, J.D. Andres, E. Jimenez, I. Espinosa-Martos, J. Rodriguez, and M. S. D. Pipaon. 2014. PO-0607c administration of Bifidobacterium breve and Lactobacillus salivarius, two strains isolated from human milk, to very low and extremely low birth weight preterm infants: A pilot study. Arch. Dis. Child 99:A451.3A452.

Fang, M. Y. 2012. The screening of acid-resistant Bifidobacterium from human resource and the evaluation of the capacity. Shanghai Jiaotong University, China. [in Chinese]

Feng, W. H., and Y. L. Chang. 2012. The optimization of liquid fermentation conditions and the determination of growth curve for Bifidobacterium longum. China Medical Herald. 9:115-117. [in Chinese]

Fernández, L., N. Cárdenas, R. Arroyo, S. Manzano, E. Jiménez, V. Martín, and J. M. Rodríguez. 2016. Prevention of infectious mastitis by oral administration of Lactobacillus salivarius PS2 during late pregnancy. Clin. Infect. Dis. 62:568-573. https://doi.org/10 $.1093 / \mathrm{cid} / \mathrm{civ} 974$.

Fernández, L., S. Langa, V. Martín, A. Maldonado, E. Jiménez, R. Martín, and J. M. Rodríguez. 2013. The human milk microbiota: Origin and potential roles in health and disease. Pharmacol. Res. 69:1-10. https://doi.org/10.1016/j.phrs.2012.09.001.

Ferraris, L., J. Aires, A. J. Waligora-Dupriet, and M. J. Butel. 2010. New selective medium for selection of bifidobacteria from human feces. Anaerobe 16:469-471. https://doi.org/10.1016/j.anaerobe .2010.03.008.

Gao, S., Y. Qiao, Y. W. Zhang, Q. Peng, Z. S. Zhang, B. Shi, J. M. Li, and Y. Wu. 2017. Isolation, identification and probiotic characterization of lactic acid bacteria in human breast milk. Science and Technology of Food Industry. 10:205-210. [in Chinese]

Gu, R. X., Z. Q. Yang, Z. H. Li, S. L. Chen, and Z. L. Luo. 2008. Probiotic properties of lactic acid bacteria isolated from stool samples of longevous people in regions of Hotan, Xinjiang and Bama, 
Guangxi, China. Anaerobe 14:313-317. https://doi.org/10.1016/j .anaerobe.2008.06.001.

Heikkilä, M. P., and P. E. J. Saris. 2003. Inhibition of Staphylococcus aureus by the commensal bacteria of human milk. J. Appl. Microbiol. 95:471-478. https://doi.org/10.1046/j.1365-2672.2003 $.02002 . x$.

Hennet, T., and L. Borsig. 2016. Breastfed at Tiffany's. Trends Biochem. Sci. 41:508-518. https://doi.org/10.1016/j.tibs.2016.02.008.

Hojsak, I., N. Snovak, S. Abdović, H. Szajewska, Z. Mišak, and S. Kolaček. 2010. Lactobacillus GG in the prevention of gastrointestinal and respiratory tract infections in children who attend day care centers: A randomized, double-blind, placebo-controlled trial. Clin. Nutr. 29:312-316. https://doi.org/10.1016/j.clnu.2009 .09 .008

Holzapfel, W. H., P. Haberer, R. Geisen, J. Björkroth, and U. Schillinger. 2001. Taxonomy and important features of probiotic microorganisms in food and nutrition. Am. J. Clin. Nutr. 73:365S-373S. https://doi.org/10.1093/ajen/73.2.365s.

Hunt, K. M., J. A. Foster, L. J. Forney, U. M. E. Schütte, D. L. Beck, Z. Abdo, L. K. Fox, J. E. Williams, M. K. McGuire, and M. A. McGuire. 2011. Characterization of the diversity and temporal stability of bacterial communities in human milk. PLoS One 6:e21313. https://doi.org/10.1371/journal.pone.0021313.

Iwase, T., Y. Uehara, H. Shinji, A. Tajima, H. Seo, K. Takada, T. Agata, and Y. Mizunoe. 2010. Staphylococcus epidermidis Esp inhibits Staphylococcus aureus biofilm formation and nasal colonization. Nature 465:346-349. https://doi.org/10.1038/nature09074.

Jiménez, E., J. De Andrés, M. Manrique, P. Pareja-Tobes, R. Tobes, J. F. Martínez-Blanch, F. M. Codoñer, D. Ramón, L. Fernández, and J. M. Rodríguez. 2015. Metagenomic analysis of milk of healthy and mastitis-suffering women. J. Hum. Lact. 31:406-415. https:// doi.org/10.1177/0890334415585078.

Kozak, K., D. Charbonneau, R. Sanozky-Dawes, and T. Klaenhammer. 2015. Characterization of bacterial isolates from the microbiota of mothers' breast milk and their infants. Gut Microbes 6:341-351. https://doi.org/10.1080/19490976.2015.1103425.

Kvist, L. J. 2010. Toward a clarification of the concept of mastitis as used in empirical studies of breast inflammation during lactation. J. Hum. Lact. 26:53-59. https://doi.org/10.1177/0890334409349806.

Liu, Z., Z. Jiang, K. Zhou, P. Li, G. Liu, and B. Zhang. 2007. Screening of bifidobacteria with acquired tolerance to human gastrointestinal tract. Anaerobe 13:215-219. https://doi.org/10.1016/j .anaerobe.2007.05.002.

Mandal, H., R. Jariwala, and T. Bagchi. 2016. Isolation and characterization of lactobacilli from human faeces and indigenous fermented foods for their potential application as probiotics. Can. J. Microbiol. 62:349-359. https://doi.org/10.1139/cjm-2015-0576.

Manini, F., M. Casiraghi, K. Poutanen, M. Brasca, D. Erba, and C. Plumed-Ferrer. 2016. Characterization of lactic acid bacteria isolated from wheat bran sourdough. Lebensm. Wiss. Technol. 66:275-283. https://doi.org/10.1016/j.lwt.2015.10.045

Martín, R., E. Jiménez, H. Heilig, L. Fernández, M. L. Marín, E. G. Zoetendal, and J. M. Rodríguez. 2009. Isolation of bifidobacteria from breast milk and assessment of the bifidobacterial population by PCR-denaturing gradient gel electrophoresis and quantitative real-time PCR. Appl. Environ. Microbiol. 75:965-969. https://doi .org/10.1128/AEM.02063-08.

Martín, R., S. Langa, C. Reviriego, E. Jiménez, M. L. Marín, M. Olivares, J. Boza, J. Jiménez, L. Fernández, J. Xaus, and J. M. Rodríguez. 2004. The commensal microflora of human milk: New perspectives for food bacteriotherapy and probiotics. Trends Food Sci. Technol. 15:121-127. https://doi.org/10.1016/j.tifs.2003.09 .010 .

Martín, R., S. Langa, C. Reviriego, E. Jimínez, M. L. Marín, J. Xaus, L. Fernández, and J. M. Rodríguez. 2003. Human milk is a source of lactic acid bacteria for the infant gut. J. Pediatr. 143:754-758. https://doi.org/10.1016/j.jpeds.2003.09.028.

Morales, F., J. I. Morales, C. H. Hernández, and H. Hernández-Sánchez. 2011. Isolation and partial characterization of halotolerant lactic acid bacteria from two Mexican cheeses. Appl. Biochem.
Biotechnol. 164:889-905. https://doi.org/10.1007/s12010-011 -9182-6.

Muñoz-Quezada, S., E. Chenoll, J. María Vieites, S. Genovés, J. Maldonado, M. Bermúdez-Brito, C. Gomez-Llorente, E. Matencio, M. José Bernal, F. Romero, A. Suárez, D. Ramón, and A. Gil. 2013. Isolation, identification and characterisation of three novel probiotic strains (Lactobacillus paracasei CNCM I-4034, Bifidobacterium breve CNCM I-4035 and Lactobacillus rhamnosus CNCM I-4036) from the faeces of exclusively breast-fed infants. Br. J. Nutr. 109(S2):S51-S62. https://doi.org/10.1017/S0007114512005211.

Murphy, K., D. Curley, T. F. O'Callaghan, C. A. O'Shea, E. M. Dempsey, P. W. O'Toole, R. P. Ross, C. A. Ryan, and C. Stanton. 2017. The composition of human milk and infant faecal microbiota over the first three months of life: A pilot study. Sci. Rep. 7:40597. https://doi.org/10.1038/srep40597.

Nawaz, M., J. Wang, A. P. Zhou, C. F. Ma, X. K. Wu, and J. R. Xu. 2011. Screening and characterization of new potentially probiotic lactobacilli from breast-fed healthy babies in Pakistan. Afr. J. Microbiol. Res. 5:1428-1436. https://doi.org/10.5897/AJMR10.737.

Österlund, P., T. Ruotsalainen, R. Korpela, M. Saxelin, A. Ollus, P. Valta, M. Kouri, I. Elomaa, and H. Joensuu. 2007. Lactobacillus supplementation for diarrhoea related to chemotherapy of colorectal cancer: A randomised study. Br. J. Cancer 97:1028-1034. https: //doi.org/10.1038/sj.bjc.6603990.

Patel, A., J. B. Prajapati, O. Holst, and A. Ljungh. 2014. Determining probiotic potential of exopolysaccharide producing lactic acid bacteria isolated from vegetables and traditional Indian fermented food products. Food Biosci. 5:27-33. https://doi.org/10.1016/j .fbio.2013.10.002.

Rescigno, M., G. Rotta, B. Valzasina, and P. Ricciardi-Castagnoli. 2001. Dendritic cells shuttle microbes across gut epithelial monolayers. Immunobiology 204:572-581. https://doi.org/10.1078/0171 $-2985-00094$

Riaz Rajoka, M. S., H. M. Mehwish, M. Siddiq, Z. Haobin, J. Zhu, L. Yan, D. Shao, X. Xu, and J. Shi. 2017. Identification, characterization, and probiotic potential of Lactobacillus rhamnosus isolated from human milk. Lebensm. Wiss. Technol. 84:271-280. https:// doi.org/10.1016/j.lwt.2017.05.055.

Riaz Rajoka, M. S., H. Zhao, Y. Lu, Z. Lian, N. Li, N. Hussain, D. Shao, M. Jin, Q. Li, and J. Shi. 2018. Anticancer potential against cervix cancer (HeLa) cell line of probiotic: Lactobacillus casei and Lactobacillus paracasei strains isolated from human breast milk. Food Funct. 9:2705-2715. https://doi.org/10.1039/C8FO00547H.

Ruiz, L., C. García-Carral, and J. M. Rodriguez. 2019. Unfolding the human milk microbiome landscape in the omics era. Front. Microbiol. 10:1378. https://doi.org/10.3389/fmicb.2019.01378.

Sakwinska, O., D. Moine, M. Delley, S. Combremont, E. Rezzonico, P. Descombes, G. Vinyes-Pares, Y. Zhang, P. Wang, and S. K. Thakkar. 2016. Microbiota in breast milk of Chinese lactating mothers. PLoS One 11:e0160856. https://doi.org/10.1371/journal.pone .0160856 .

Shin, S. P., Y. M. Choi, W. H. Kim, S. P. Hong, J. M. Park, J. Kim, O. Kwon, E. H. Lee, and K. B. Hahm. 2018. A double blind, placebo-controlled, randomized clinical trial that breast milk derivedLactobacillus gasseri BNR17 mitigated diarrhea-dominant irritable bowel syndrome. J. Clin. Biochem. Nutr. 62:179-186. https://doi .org/10.3164/jcbn.17-73.

Solís, G., C. G. de los Reyes-Gavilan, N. Fernández, A. Margolles, and M. Gueimonde. 2010. Establishment and development of lactic acid bacteria and bifidobacteria microbiota in breast-milk and the infant gut. Anaerobe 16:307-310. https://doi.org/10.1016/j .anaerobe.2010.02.004

Španová, A., V. Dráb, K. Turková, M. Špano, R. Burdychová, O. Šedo, D. Šrůtková, V. Rada, and B. Rittich. 2015. Selection of potential probiotic Lactobacillus strains of human origin for use in dairy industry. Eur. Food Res. Technol. 241:861-869. https://doi.org/10 .1007/s00217-015-2511-1.

Tamura, K., J. Dudley, M. Nei, and S. Kumar. 2007. MEGA4: Molecular evolutionary genetics analysis (MEGA) software version 4.0 
Mol. Biol. Evol. 24:1596-1599. https://doi.org/10.1093/molbev/ msm092.

Tanaka, H., K. Doesburg, T. Iwasaki, and I. Mierau. 1999. Screening of lactic acid bacteria for bile salt hydrolase activity. J. Dairy Sci. 82:2530-2535. https://doi.org/10.3168/jds.S0022-0302(99)75506 -2 .

Tulumoglu, S., Z. N. Yuksekdag, Y. Beyatli, O. Simsek, B. Cinar, and E. Yaşar. 2013. Probiotic properties of lactobacilli species isolated from children's feces. Anaerobe 24:36-42. https://doi.org/10.1016/ j.anaerobe.2013.09.006.

Tuo, Y., W. Zhang, L. Zhang, L. Ai, Y. Zhang, X. Han, and H. Yi. 2013. Study of probiotic potential of four wild Lactobacillus rhamnosus strains. Anaerobe 21:22-27. https://doi.org/10.1016/j .anaerobe.2013.03.007.

Tuo, Y. F., W. Q. Zhang, L. W. Zhang, and L. Z. Ai. 2012. Assessment of the probiotc properties of Lactobacillus strains. Xiandai Shipin Keji XX:28. [in Chinese]

Verdenelli, M. C., F. Ghelfi, S. Silvi, C. Orpianesi, C. Cecchini, and A. Cresci. 2009. Probiotic properties of Lactobacillus rhamnosus and Lactobacillus paracasei isolated from human faeces. Eur. J. Nutr. 48:355-363. https://doi.org/10.1007/s00394-009-0021-2.

Verhasselt, V. 2010. Neonatal tolerance under breastfeeding influence. Curr. Opin. Immunol. 22:623-630. https://doi.org/10.1016/j.coi 2010.08.008
Walker, D. K., and S. E. Gilliland. 1993. Relationships among bile tolerance, bile salt deconjugation, and assimilation of cholesterol by Lactobacillus acidophilus. J. Dairy Sci. 76:956-961. https://doi .org/10.3168/jds.S0022-0302(93)77422-6.

Wang, S. M., L. W. Zhang, R. B. Fan, X. Han, H. X. Yi, L. L. Zhang, C. H. Xue, H. B. Li, Y. H. Zhang, and N. Shigwedha. 2014. Induction of HT-29 cells apoptosis by lactobacilli isolated from fermented products. Res. Microbiol. 165:202-214. https://doi.org/10 .1016/j.resmic.2014.02.004.

World Health Organization. 2003. Global Strategy for Infant and Young Child Feeding. World Health Organization, Geneva, Switzerland.

Zhang, D. R. 2012. Applications of microecology in the field of medicine. Zhongguo Weishengtaixue Zazhi 14:3-4. [in Chinese]

Zhao, F., Y. Q. Li, and B. C. Li. 2016. Screening of probiotic Lactobacillus in simulated gastrointestinal Environment. Microbiology China. 43:1396-1403. [in Chinese]

Zhu, Q. H., L. P. He, L. Zhang, B. Gao, C. Q. Li, and J. Xiong. 2017. Screening and tolerance evaluation of cholesterol-lowering Bifidobacterium BZ11. China Brewing. 301:54-58. [in Chinese] 